


\section{¿De qué color son las ciudades? Metodologías de apreciación cromática urbana ${ }^{1}$ What color are the cities? Methodologies of urban chromatic appreciation}

\section{Resumen:}

\section{Palabras clave:}

Color, ciudad, metodología, percepción

Key words:

Color, city, methodology, perception

Recibido: 10 -jul- 2013 Aceptado: 21 -oct- 2013
*Diseñador Gráfico y Joven Investigador de la Universidad de Boyacá. carrodriguez@uniboyaca.edu.co

${ }^{1}$ Revisión de tema resultante de la etapa inicial de la investigación Colores de la ciudad imaginada, financiada por el Departamento Administrativo de Ciencia, Tecnología e Innovación de Colombia (Colciencias) y la Universidad de Boyacá dentro del convenio Beca - Pasantía Jóvenes investigadores e innovadores 2012
El presente artículo de revisión de tema hace parte de la investigación "Colores de la ciudad imaginada", que en su etapa inicial realizó una revisión bibliográfica referente a metodologías implementadas en investigaciones del color de las ciudades. Se abordaron métodos de estudio del color urbano desde dos enfoques: el color físico de las ciudades y el percibido por los habitantes. En el estudio del color físico se toman en consideración autores como Phillipe Lenclos y Cristina Boeri, así como estudios locales planteados en la Universidad de Caldas. Respecto al estudio del color imaginado se cita el trabajo de imaginarios urbanos de Armando Silva, el proyecto desarrollado por BMW en Barcelona $e$ investigaciones en el contexto boyacense que siguen la metodología de estudio de los imaginarios. Finalmente, el artículo se remite a ejemplos de intervenciones e interpretaciones del color de la ciudad en campos como el arte y el diseño.

\section{Abstract}

This review of topic article is part of the investigation Colors of the imaginary city, whose initial stage was focused on literature review about methodologies applied in urban color research. The urban color study methods were approached from two perspectives: the physical color of the cities and the color perceived by the inhabitants. Authors like Phillipe Lenclos and Cristina Boeri, as well as local studies developed in the University of Caldas were considered to analyze the physical color. In relation to the imaginary color a number of sources were quoted: Armando Silva's studies of urban imaginary, BMW project in Barcelona and research in the context of Boyacá following the methodology of tackling the imaginary. Finally, the article provides examples of interventions and interpretations of urban color in fields such as arts and design. 
El color de una ciudad, de un barrio o de un pueblo es el color de sus recintos, el color de sus casas y edificios, el color de su historia y de sus gentes. La multiplicidad de los colores del espacio urbano refleja la multiplicidad de sus habitantes y de los elementos de la cultura colectiva que allí ha nacido, se desarrolla y actúa como suía de la vida cotidiana.

(Saldarriaga, 1984, p. 11).

Desde que la humanidad dio nombres como verde, rojo o azul a las diferentes radiaciones electromagnéticas reflejadas por los objetos, los colores han sido un componente fundamental de nuestra percepción del mundo. Los asociamos a sensaciones, estímulos, valores de gusto e información, y aun viviendo en un contexto digital 3D donde los colores han dejado de sorprendernos, seguimos siendo seres que nos vestimos de colores, acogemos señales de colores y vivimos en ciudades de colores.

Tal y como lo afirma Juan Carlos Sanz (1993), en El libro del color, la función primigenia de los colores es la de significar conceptos, para así establecer una relación comunicativa entre el individuo y el ambiente físico. Así pues, muchas de nuestras habilidades analíticas del entorno parten de nuestra capacidad de distinguir diferentes tonalidades y asociarlas a significados distintos, los cuales están siempre condicionados por el contexto. En ese sentido, Umberto Eco (1986), puntualiza que el mensaje está condicionado por cierta indeterminación, generada por factores que contribuyen al sentido del mismo, como son la referencia a un universo 
de mensajes precedentes, las perspectivas ideológicas y las circunstancias en que se da la comunicación.

Según Joan Costa (2003), el color por sí solo no es un transmisor de información. Es importante entender que el contexto determina las sensaciones, los significados y las interpretaciones que puede tener una tonalidad, si bien estas últimas, en ocasiones, son similares o están influenciadas unas por otras. Es muy diferente, por ejemplo, lo comunicado por el casco verde del obrero que lo comunicado por el lazo verde de la paz: aunque se trata del mismo color, se encuentra en un diferente escenario.

De acuerdo con esto, nuestro entorno es transmisor de sensaciones por excelencia, lo cual conlleva a que sea también un emisor de colores. Casos como el barrio de la Boca en Buenos Aires, evidentemente reconocido por sus llamativas fachadas de colores; la ciudad de Tirana en Albania, donde las fachadas de los edificios se pintaron de forma multicolor para proyectar una nueva imagen de ciudad; o Ráquira en Boyacá, un pueblo que proyecta en las fachadas de sus casas la diversidad y el colorido de sus productos artesanales, particularidad que le ha otorgado fama y reconocimiento como lugar turístico de la región, han llevado a investigadores a preguntarse de qué color son las ciudades y qué incidencia tiene el color de éstas en la vida de sus habitantes. Todo ello ha propiciado el estudio del color urbano.

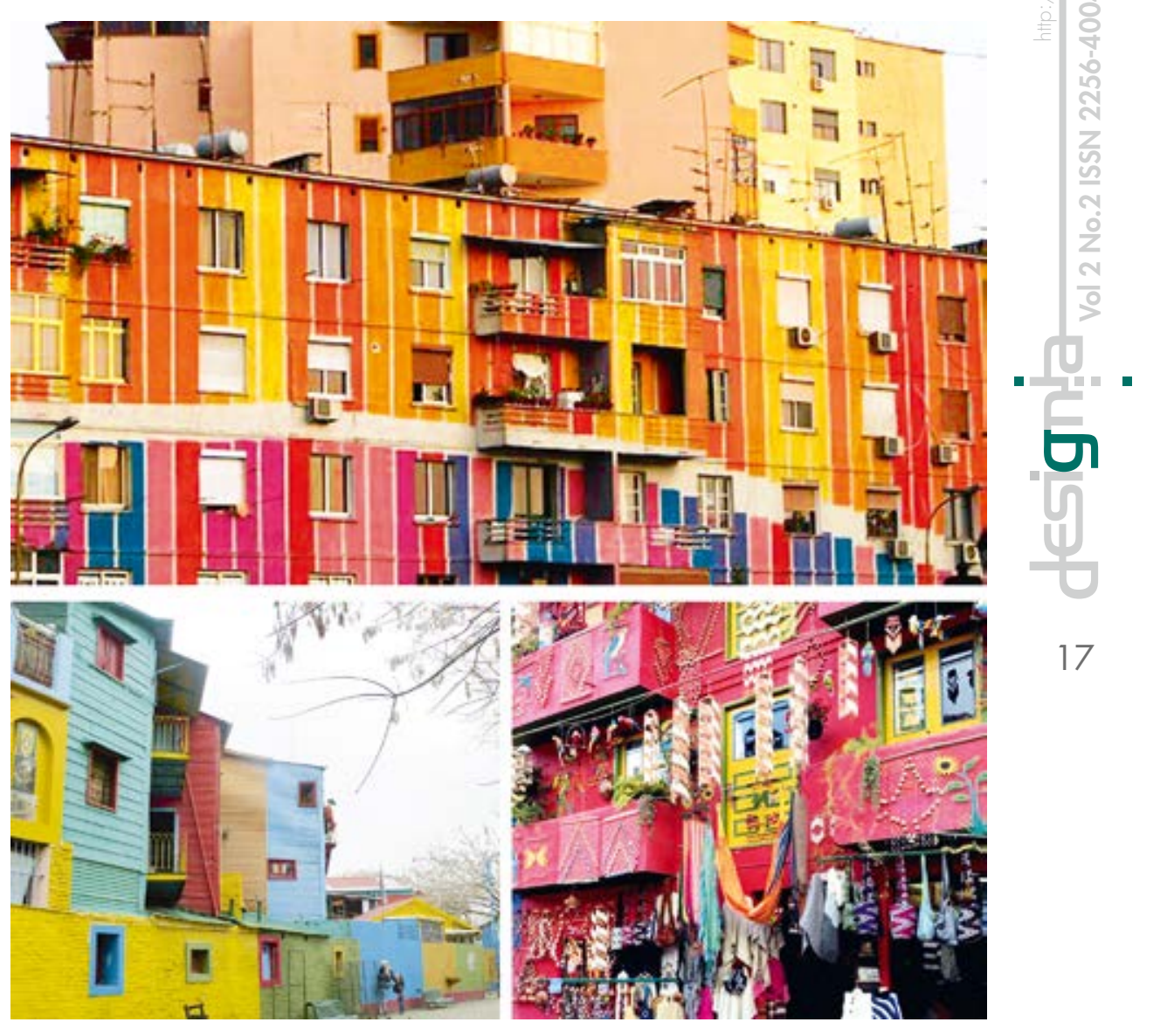

Figura 1. Superior: Tirana (Albania), Inferior derecha: Ráquira (Boyacá, Colombia); Inferior izquierda: Caminito en el Barrio de la Boca (Buenos Aires Argentina). Fuente: Nancy Quiroga (Investigadora Grupo Xisqua). Wade Shepard http://www.vagabondjourney.com 


\section{VARIABLES QUE CONDICIONAN EL ESTUDIO DEL COLOR URBANO}

Las impresiones evocadas por un ambiente urbano dependen de las interacciones cualitativas de varios elementos. En este sentido, el color puede ayudar a determinar la jerarquía visual de un espacio urbano, por ejemplo, el sentido de unidad y continuidad. (Boeri, 2010)ㄹ.

Las ciudades no son estáticas y al igual que quienes las conforman, son organismos cambiantes y en constante movimiento. Las ciudades se renuevan, se deterioran, se engalanan, permanecen y se transforman. Asimismo, su color es el reflejo de un momento y puede variar con el tiempo de acuerdo con diferentes variables que inciden en dichos cambios. Esas variables han sido tomadas en consideración por investigadores cuyos estudios permiten identificar los factores de variación.

Boeri (2010) hace énfasis en las variables que deben tenerse en cuenta antes de realizar un estudio del color urbano. Inicialmente, esta autora reflexiona acerca de dos de ellas que pueden influir en la identificación de tal color: los colores permanentes y los colores aleatorios de los lugares, entendidos como aquellos elementos estables y cambiantes en la imagen urbana, respectivamente.

Los colores permanentes son aquellos constantes, en esta categoría de análisis, el objeto de estudio es el color de fachadas, puertas, monumentos o calles. Por otra parte, los colores aleatorios o efímeros son aquellos factores que inciden en los cambios en la percepción del color, como son el clima, la luz, el vestido de los habitantes, la decoración navideña, la hora del día y la época del año.

Además de las variables señaladas previamente, la arquitecta italiana propone en su

${ }^{2}$ Originalmente en inglés, traducción al español del autor tesis tres contextos desde los que es posible desarrollar un estudio del color de la ciudad: contexto espacial, cultural y temporal. A su vez, estos involucran una serie de factores y valores relacionados entre sí. 


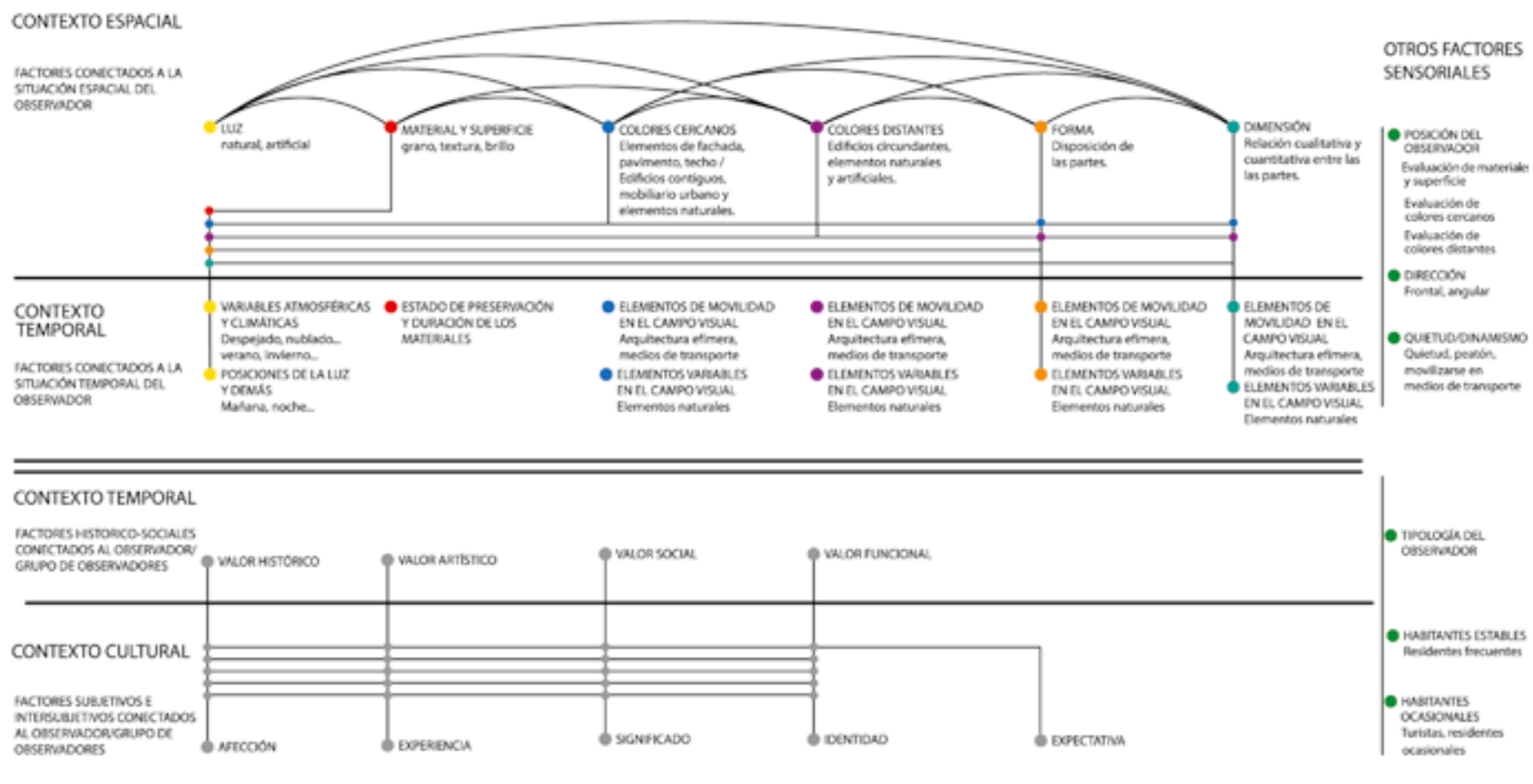

Figura 2. Mapa de síntesis de factores y relaciones que contribuyen a la percepción del color en un espacio urbano. Fuente: Boeri $(2010)^{3}$.

${ }^{3}$ Originalmente en inglés, traducción al español del autor.
En primer lugar, el contexto de la espacialidad aborda aquellos factores conectados a la situación física del entorno. De esta manera, la luz, los materiales de construcción, la distancia y cercanía de los colores observados, la forma y dimensión de las construcciones, condicionan los matices de una ciudad. Asimismo, en el contexto temporal se consideran factores conectados a la situación estacional del entorno, en este caso, el clima, el estado de preservación de los materiales, las variaciones en la naturaleza, los eventos y las fechas especiales son condicionantes de variaciones cromáticas.

Finalmente, el contexto cultural toma en cuenta factores históricos, sociales y subjetivos relacionados con el ciudadano y con lo que este infiere de la ciudad, es decir, la experiencia del habitante y sus sentimientos de afección e identidad. El género, la edad y el tiempo vivido en un determinado lugar, así como ciertas características socialmente aceptadas, relacionadas con el valor histórico y el significado de los espacios, también condicionan el color percibido por las personas. 


\section{CONSIDERACIONES DEL COLOR DE LA CIUDAD}

En cada país en el mundo, la gente ama preservar sus viviendas. Al pintar y decorar buscan no solo proteger los materiales del riesgo que significa cambiar, descomponerse o derrumbarse; también esperan 'hacerla hermosa', identificarla con un grupo, o por el contrario, marcar una diferencia que obedece a tradiciones sociales y religiosas. (Lenclos, 1999, p. 48) $)^{4}$.

El estudio del color urbano se destaca por la diversidad de disciplinas que lo han abordado. Arquitectos, psicólogos, semiólogos, diseñadores y artistas han tratado el tema con una perspectiva particular, que de acuerdo con los contextos señalados anteriormente, muestran dos enfoques desde los cuales se han planteado las investigaciones. Por una parte se encuentra el color físico, relacionado con los componentes formales de una ciudad, tales como calles y fachadas, y de otro lado, el color imaginado responde a las percepciones de los habitantes y las relaciones cognoscitivas existentes entre el entorno y el observador.

Si bien dichos enfoques marcan dos grandes vertientes en los estudios del color, no siempre son tan distantes uno del otro. Ejemplo de ello es el trabajo realizado por María Mercedes Ávila (2010), quien en investigaciones desarrolladas en el Instituto del Color de la Universidad Nacional de Córdoba (Argentina), aborda el color urbano desde la forma, la expresión y el significado. Su propuesta hace un planteamiento del color como material de construcción de la ciudad, ya sea en su aplicación publicitaria, corporativa o arquitectónica, y toma en consideración tanto el aspecto físico urbano como la percepción del habitante y su propia experiencia.

Del mismo modo, señala a las fachadas como el componente de mayor protagonismo, pues en su mayoría, proyectan información cromática proveniente de tonos de pintura, materiales de construcción y elementos publicitarios, los cuales son organizados mentalmente por el ciudadano y enlazados a recuerdos, experiencias y gustos que se traducen en el imaginario del color. 
A su vez, varios estudios se han enfocado exclusivamente en el color urbano desde lo tangible o lo intangible. A continuación se presentan casos en que la gran diferencia metodológica corresponde a la mirada a la ciudad desde el enfoque del investigador, pues bien puede tratarse de un exhaustivo proceso de observación en el trabajo de campo, o de aproximaciones desde la perspectiva del habitante, más relacionadas con ejercicios de participación ciudadana.

Estudio del color físico de las ciudades.

Esta característica cromática, referida al color de fachadas y calles, estudia los pigmentos que conforman la imagen urbana y son físicamente comprobables.

Precisamente en este campo, el diseñador francés Jean Phillipe Lenclos es pionero. Su análisis se fundamenta en la "geografía del color", teoría desarrollada durante su trabajo como colorista alrededor del mundo y que es sintetizada en la publicación Colors of the World (1999):

La investigación de Geografía del color originada en los años sesenta, está basada en la observación metodológica y analítica de varios componentes visuales que contribuyen a la individualización del hábitat. De hecho, esta es la herramienta más práctica para delimitar claramente las tonalidades que constituyen un lugar (Lenclos, 1999, p. 17) $)^{5}$.

De acuerdo con la tesis planteada por Lenclos, cada ciudad posee una información cromática que la hace única y se relaciona directamente con su patrimonio cultural e

${ }^{5}$ Originalmente en inglés, traducción al español del autor. histórico, al tiempo que contribuye a la construcción de un sentido de pertenencia e identidad local. Por consiguiente, el color de las ciudades es un reflejo del momento vivido por sus habitantes, de su pasado y proyección hacia el futuro.

Para sustentar su proposición, Lenclos ha desarrollado una metodología fundamentada en el uso de distintas herramientas: observación directa, toma de muestras de materiales, realización de dibujos en el lugar, comparación y sistematización de la información por medio de cuadros de color. Todo esto apunta a la obtención de paletas de color para los sitios estudiados, que son el objetivo final del análisis de cada caso. 
Los estudios realizados en ciudades como Argel (Argelia), San Francisco (Estados Unidos) y Murotsu (Japón), se enfocan en la identificación de valores cromáticos, especialmente en fachadas vernáculas de la arquitectura local de los pueblos, por lo general mediante el estudio de 25 casos en cada lugar. La metodología aplicada en el análisis de un sitio se desarrolla deductivamente bajo los siguientes lineamientos:

\section{Fase A - Análisis del sitio}

- A1 Muestras de materiales: se efectúa un examen meticuloso del sitio, por medio de la toma de muestras de materiales que constituyen un acercamiento inicial al color urbano.

- A2 Reproducción del color: se desarrolla mediante un trabajo comparativo con guías de color.

- A3 Dibujo a color del sitio: el dibujo es una herramienta eficiente y rápida para capturar y sintetizar visualmente el color.

- A4 Fotografía: este es un recurso indispensable para registrar el lugar.

\section{Fase B - Síntesis visual de los hallazgos cromáticos}

- B1 Paleta general: se desarrolla una paleta que reproduce los colores predominantes del lugar y aborda elementos del paisaje como la vegetación.

- B2 Paleta general de fachadas: centrada solamente en el estudio del color de las fachadas de casas y edificios.

- B3 Paleta selectiva: considera elementos como puertas, ventanas y marcos.

- B4 Paleta de relaciones cualitativas y cuantitativas: se desarrolla un catálogo de colores para cada uno de los elementos estructurales de un edificio (techo, paredes, puertas, ventanas). Este proceso destaca las relaciones estadísticas de los colores encontrados. - B5 Paleta cromática: comprende el ensamble de los componentes analizados. Esta paleta ilustra los colores dominantes de los distintos elementos y permite establecer una estadística visual de los colores más utilizados en el sitio.

- B6 Cuadro de síntesis: finalmente se elabora este cuadro, obtenido por la imposición de elementos de la paleta selectiva sobre la paleta general.
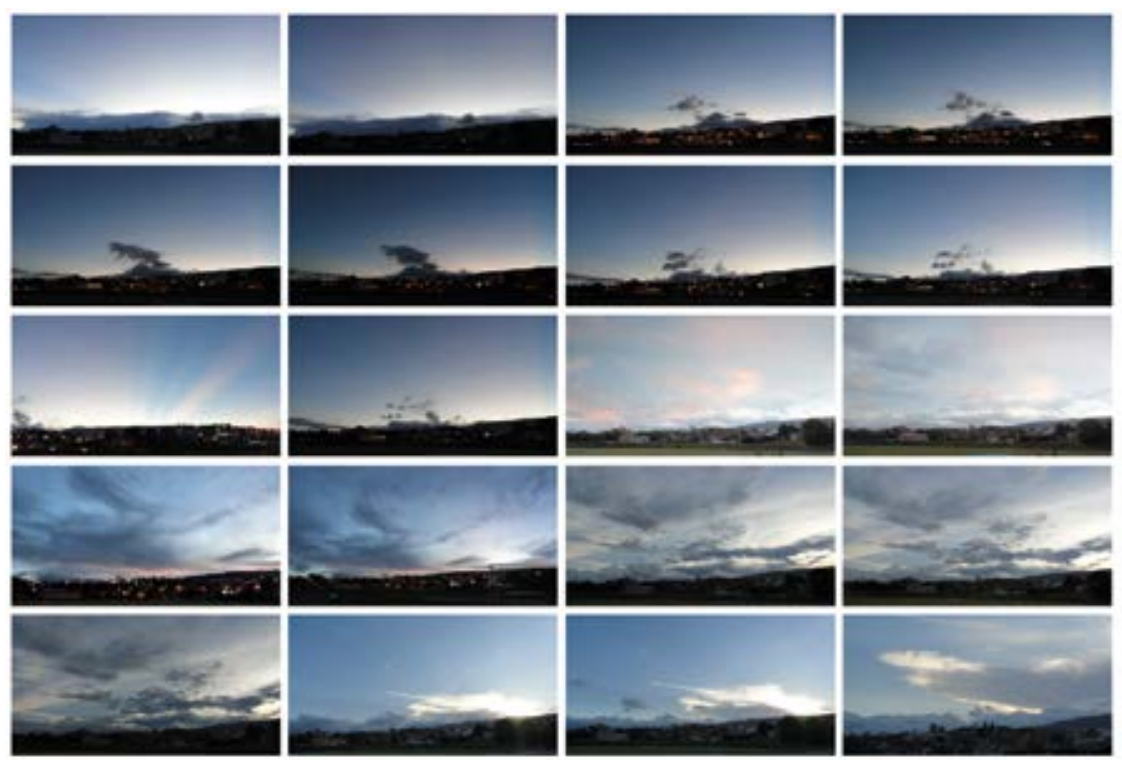

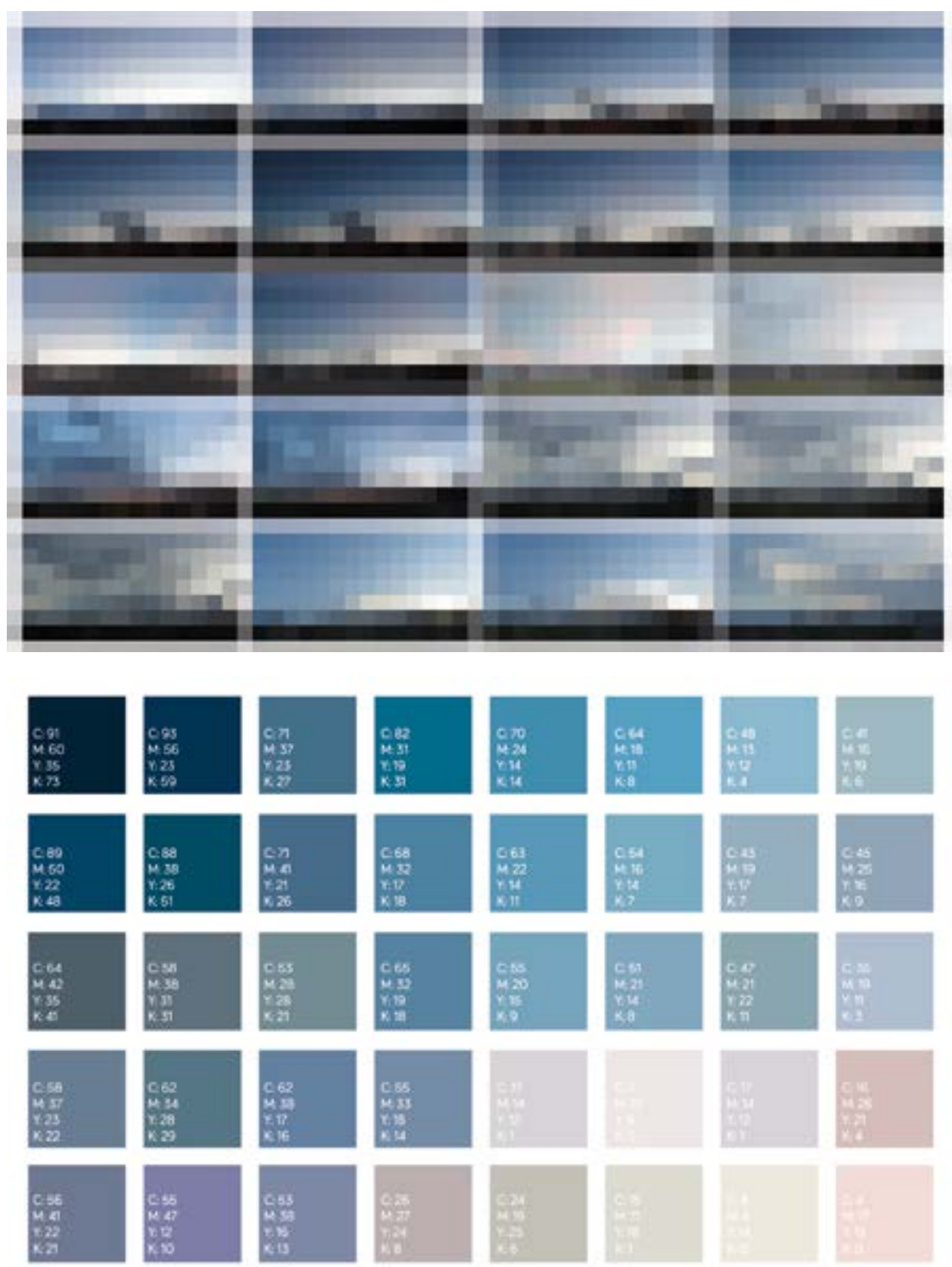

Figura 3. Ejercicio de desarrollo de paleta de color "Atardecer de Tunja" basado en las metodologías de Lenclos (1999) y Gómez (2006). A1 Registro fotográfico realizado de 5:30 a 6:00 pm durante cuatro meses. A2 Proceso de pixelación de las imágenes. A3 Síntesis del color y planteamiento de paleta. Fuente: Autor. 
En Colombia, los trabajos de Saldarriaga (1984) y Gómez (2006), dan cuenta de estudios pioneros del color físico de las ciudades en el país. En Los colores de la calle, Saldarriaga aborda el color del entorno a partir de una búsqueda fotográfica de los valores cromáticos de diferentes municipios. Así, se concentra en las fachadas de las casas de los barrios populares desde una mirada al color y a su apropiación cultural, al entenderlo como un reflejo de la idiosincrasia del habitante y el lazo que une diversos componentes de un pueblo (historia, costumbres y formas de expresión). Ahora bien, al enfocarse específicamente en las fachadas, se generalizan las características y los elementos arquitectónicos de las casas. A su vez, no se concluye con el desarrollo de una paleta de color, pero se trata de un claro ejemplo sobre como a partir de la fotografía es posible configurar una imagen urbana que da cuenta de la relación del habitante con el espacio, de la forma como las personas se apropian del mismo y de la riqueza cromática de las calles colombianas, propia de la estética popular latinoamericana.
Por su parte, la investigación desarrollada en la Universidad de Caldas propone la producción de una síntesis cromática de los pueblos del departamento en un banco de información cromática, por medio de paletas de color. El estudio Interpretación visual de los valores cromáticos regionales en Caldas (Gómez, 2006), abordado es de los contextos cultural y espacial, aplica la teoría del color con relación a la información visual (fotografías y muestras de color) registrada en los diferentes municipios. Para cada uno se consideran tres líneas temáticas (paisaje, arquitectura y expresión popular regional), con el objetivo de sintetizar datos cromáticos e identificar, de este modo, el carácter y el espíritu de los distintos lugares. De tal manera, se establece que:

\section{El esquema de color de una calle o manzana puede tener un efecto considerable sobre el carácter y la apariencia de los espacios públicos. El color puede contribuir a la unidad del entorno o por el contrario, a fragmentar la ciudad y sus componentes. Del mismo modo, el color usado en las calles tiene la habilidad para crear carácter y 'senius loci', es decir, definir el espíritu de cada lugar. (Gómez, 2006, p. 76).}

El proceso metodológico del proyecto abarca desde la estética popular hasta la teoría del color, y emplea instrumentos como registros fotográficos, fichas tipológicas y pixelación de imágenes, lo cual conduce a la identificación de paletas de color para cada municipio. De tal modo, se plantean escalas cromáticas que reflejan el contexto y la identidad de cada sitio en un banco departamental de información cromática. 


\section{Estudio del color imaginado o percibido por los habitantes}

En este contexto se estudia la percepción cognoscitiva de los habitantes respecto al color de la ciudad. Por lo tanto, se remite a la teoría de los imaginarios urbanos y a las construcciones mentales elaboradas por las personas en el ejercicio de ser ciudadanos.

La investigación desarrollada por Silva (2006) es un claro referente de las relaciones cognoscitivas que se construyen entre los habitantes de una ciudad y de cómo ello es una forma de apropiar el lugar donde se reside. En este trabajo surgen observaciones acerca de la manera en que lo imaginario afecta lo real y de cómo un acontecimiento se puede magnificar imaginariamente a través de procesos de narración urbana. Las técnicas planteadas por Silva (fotografía, estadística y narración social) son un punto de partida para posibilitar un mayor acercamiento al objeto de estudio.
Remitirse al trabajo liderado por Silva y respaldado por el Convenio Andrés Bello es fundamental para entender la metodología de análisis de los imaginarios, pues este Convenio llevó a cabo el primer estudio sobre percepción de los habitantes en Barcelona (España) y 13 ciudades latinoamericanas. En Bogotá Imaginada (Silva, 2004), primer tomo de la investigación sobre culturas urbanas, se aplicó una particular metodología de recolección de información que a partir de encuestas, fotografías y videos, permitió relacionar directamente a los habitantes con el entorno y presentar las ciudades en su esencia. El resultado de las investigaciones es una completa colección de libros con alto contenido visual que muestra las ciudades percibidas por sus propios pobladores y recorre la evolución de las mismas a partir de sus imaginarios.

En Bogotá imaginada se presenta una capital imaginada, pero mucho más real que aquella ciudad formal expuesta en enciclopedias o mapas, pues corresponde a la Bogotá construida culturalmente por sus habitantes. Es importante indicar que, por medio de métodos como la encuesta, Silva estudia los colores de esta urbe de acuerdo con la percepción de sus habitantes. Se establecen así rangos de edad que determinan impresiones diversas: para la población adulta la capital es gris, 
Cuarenta por ciento de los bogotanos percibe a su ciudad fría y gris. Cuando quisimos saber su carácter de nuevo aparecieron dos hitos en dos escalas opuestas: En la negativa Bogotá es melancólica, en la positiva es serena. Si hacemos esta proyección fantasmagórica:

\section{Bogotá = gris + melancolía + serena $(p .65-66)$}

imagen relacionada con el clima frío y sentimientos como la melancolía y la serenidad. Entre tanto, la población joven y quienes provienen de otros centros urbanos generan asociaciones con tonalidades como amarillo, azul y rojo. Esto puede

deberse a ciertos vínculos con la música (ritmos como el pop, el vallenato y la salsa), como también con sentimientos de calidez y optimismo. Silva (2004) ejemplifica estos casos de la siguiente manera:
La relación entre música y color es un hecho notable, pues los seguidores de los ritmos calientes ven a Bogotá coloreada mientras los adultos y mayores la reconocen gris [...] De este modo, en Bogotá la ecuación inicial tiende a convertirse en ésta:

\section{Bogotá = amarilla, azul y roja + cálida + optimista (p.66)}

Sin duda, el cambio de color de la ciudad, que del gris de los adultos evoluciona hacia ondas cromáticas más vivas y vistosas, como el amarillo y el rojo que perciben los jóvenes por lo general provenientes de provincias, está relacionada con el gusto musical de los entrevistados. Esta observación nos permite proponer otra ecuación, un tanto temeraria, pero que refleja la percepción imaginaria del color y la música en el nuevo milenio:

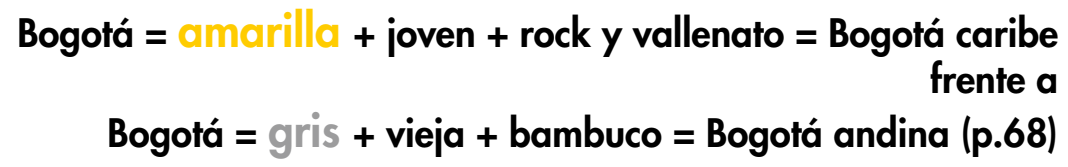


De manera similar, en Barcelona imaginada (Silva \& Escoda, 2004) se parte de la misma iniciativa mundial de los imaginarios urbanos para presentar a la capital catalana como una ciudad que la mayoría de su población percibe de color azul, tonalidad seguida por otras, entre ellas el verde y el gris, para complementar la paleta imaginada de identificación. Así, se demuestra que el color asignado a las ciudades corresponde a una construcción cultural.

Los planteamientos de Silva sirvieron como fundamento para Bogotá: La ciudad camaleónica (Kadamani
Abiyoma, 2010). En este proyecto, la autora plantea una mirada particular, surgida de una reflexión en torno al espacio público y los cambios climáticos e infraestructurales experimentados por la capital en años recientes. Igualmente, se examina cómo estas condiciones se traducen en códigos visuales y configuraciones cromáticas que permiten entender la ciudad a partir de caracterizadoras "olas de color".

Kadamani Abiyoma aborda el espacio público desde el color. Por ejemplo, compara la ola amarilla con la gran cantidad de taxis que transitan por las vías; la ola azul con los plásticos usados en los encerramientos de las construcciones que al formar líneas, invaden paulatinamente la ciudad y evidencian su proceso de transformación y renovación; mientras que la ola blanca es una metáfora de movimientos ciudadanos, como la marcha por la paz del 4 de febrero de 2008, cuya participación masiva tiñó de blanco las calles en un gesto de protesta contra la violencia. Metodológicamente, el proyecto se fundamenta en un proceso de observación y reflexión urbana desde la mirada del investigador, quien capta y sintetiza códigos de lectura gráficos y cromáticos que reflejan situaciones, características y problemáticas del espacio urbano.

Con un objetivo similar pero bajo métodos diferentes, la Iniciativa BMW para la innovación se propuso descubrir el color de Barcelona de acuerdo con la percepción de sus habitantes. Esta iniciativa se desarrolló en diferentes etapas que incluyeron sondeos en la calle, exposiciones artísticas y entrevistas formales con personajes que desde diversos campos han aportado al crecimiento de la cultura barcelonesa. 
Uno de los productos resultantes de este estudio es Colores en serie, Plata: Reflex Multicolor (Iniciativa BMW para la innovación, 2010a), un proyecto audiovisual consolidado a partir del concepto Pez de Plata Barcelona: ciudad, creación y color, que relata la experiencia de la búsqueda del color en la ciudad a través de la perspectiva de un joven, quien sufre acromatopsia ${ }^{6}$. Con el fundamento de que cada lugar se identifica mediante un color, se busca llegar a una síntesis para definir a Barcelona por medio de una tonalidad. Además, se indaga la importancia de los colores en la cotidianidad de las personas y las asociaciones entre estos y la vida diaria, los hábitos de consumo, la historia y la naturaleza. También se exponen ejemplos de lugares donde el uso del color es relevante, como los ya referidos casos del barrio de La Boca en Buenos Aires y la ciudad de Tirana en Albania, que luego de una crisis quiso proyectar una nueva imagen pintando de colores sus edificios.

Luego de una búsqueda por Barcelona, en la que el joven protagonista emplea un instrumento para transformar los colores en sonidos, se concluye que la información cromática proyectada por la ciudad española se resume en el color plateado, de acuerdo con la siguiente interpretación:

\section{Color del mar + Reflejo del sol + Gris de los caminos = Plateado}

De igual modo, se consulta a los transeúntes, a quienes les son planteadas preguntas espontáneas a modo de sondeo con el fin de examinar qué tanto saben del color y qué importancia le dan.

Además del documental, de la investigación se derivó el libro Pez de Plata: ciudad, creación y color (Iniciativa BMW para la innovación, 2010b). Este producto editorial nació como una exploración cromática de Barcelona a través de la cultura creativa que la conforma. El recorrido cultural emprendido recoge la percepción del

${ }^{6}$ Trastorno hereditario de la visión en que solo se perciben los colores blanco y negro. color de personajes como arquitectos, diseñadores, chefs y artistas, quienes viven y trabajan en la ciudad y han influido en la conformación de su imagen. En sus relatos se descubren historias de la urbe moderna, cotidiana y renovada. 
En lo concerniente a investigaciones en el contexto local, cabe citar a García (2008) quien indaga la evolución histórica del trazado urbano en Tunja y los parámetros que han determinado su desarrollo. El trabajo estudia la ocupación y el manejo de las zonas públicas y sociales en la capital boyacense, los factores incidentes en su configuración, las dinámicas urbanas y la relación de los habitantes con el espacio. En el capítulo "Imaginarios locales", al indagarse la configuración de los imaginarios urbanos y su relación con el espacio público, se expone la importancia del concepto de cultura ciudadana al que más allá de considerarse como un ejercicio se percibe como un ideal.

Pez de Plata es un claro ejemplo de productos que potencian la imagen de una ciudad, pues el análisis cromático resulta en realidad una metáfora de la diversidad de personajes existentes en Barcelona, y tal variedad remite al colorido múltiple de sus propuestas, diseños y creaciones. En consecuencia, se ofrece una nueva perspectiva del estudio del color, más apegada a la percepción de las personas y a sus historias en relación con los colores que las rondan.
La metodología utiliza encuestas que comprenden interrogantes como: ¿Le gusta vivir en Tunja?, ¿en qué ciudad le gustaría vivir?, ¿cuál es el género de Tunja? y ¿cuál es el evento que más le gusta de la ciudad? Respecto al color, se preguntó: ¿De qué color es la ciudad? El verde y el gris obtuvieron los mayores porcentajes, lo cual se explica de la siguiente manera:

Esto responde a una particularidad en especial, que se observa en el proceso de consolidación urbana. La geografía es determinante de esta lectura, vemos ladrillos y cementos, pero vemos al igual fondos naturales representados en colinas desérticas que tiñen en épocas a la ciudad, y la convierten en un paisaje mutable. La temporalidad del paisaje no se ha visto con cuidado pero constituye jerarquía y organización de la ciudad. (García, 2008, p. 70).

Guerrero (2011) también estudia la relación imaginarios urbanos - color de la ciudad en Tunja. La autora propone una hipótesis referente al notable uso del amarillo, color usado frecuentemente en las fachadas con una intención subestética de los habitantes, consistente en su anhelo por un clima cálido: 
Es probable que por coincidencia netamente cromática sea bastante significativo ver que muchas fachadas de la ciudad están pintadas de amarillo; pareciera que los almacenes de pintura no encontraran qué hacer con tan tropical color en medio de una ciudad tan fría y pareciera que lo regalaran. Otra razón del uso del amarillo puede ser que evidentemente es un color cálido y es una imagen deseada, que se hace evidente en el manejo del color (p. 31).

Según Guerrero, esta no es la única razón para la existencia de colores más populares que otros en la trama urbana. La invasión de marcas comerciales es otra variable que afecta directamente la apreciación cromática al traer consigo la popularización de las tonalidades de una marca en particular, como es el amarillo tropical de Cerveza Águila, ampliamente extendido en Tunja.

\section{INTERPRETACIONES DEL COLOR URBANO}

La idea era muy simple, quería llenar la intersección con color, que este tuviera presencia en el concurrido lugar, que resistiera el paso de carros, camiones y gente, y al mismo, tiempo interactuara con ellos.

Jessica Stockholder (Blair, 2012)

Más allá de su desarrollo teórico, algunas investigaciones proponen interpretaciones del color de la ciudad, por lo general desde disciplinas como el diseño y las artes plásticas. A continuación se presentan dos ejemplos en esta dirección, uno de ellos

${ }^{7}$ Originalmente en inglés, traducción al español del autor. desarrollado de manera pública y participativa, y otro, desde una percepción muy personal y particular. 


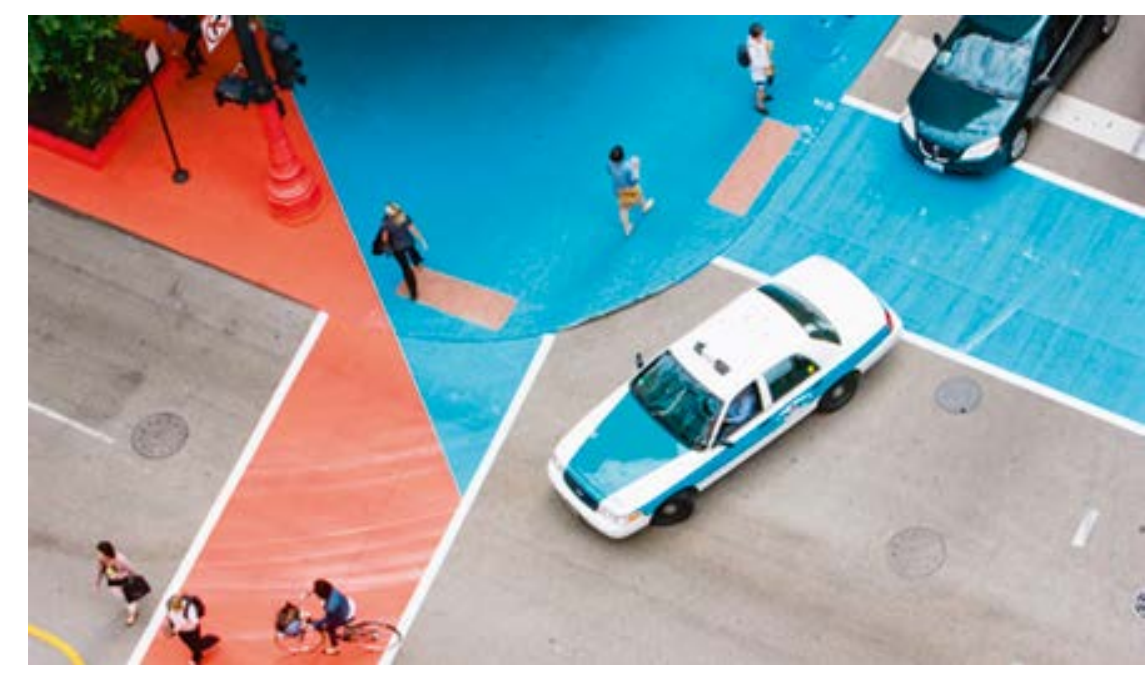

Figura 4. Vista aérea de la intervención Color Jam Fuente: Kevin Shelton, http://www. artloop.chicagoloopalliance.com

Color Jam (Stockholder, 2012) es la obra de arte público más grande en la historia de Chicago. La pieza, elaborada por la artista plástica Jessica Stockholder, consiste en un recubrimiento con vinilos de tres colores (verde, azul y rojo) de las fachadas de edificios, ventanas, calles, andenes y mobiliario urbano en la intersección de las calles State y Adams en la ciudad estadounidense.
La intervención fue realizada durante el verano de 2012 y recibió una participación masiva de comerciantes del sector, habitantes y visitantes. Este juego de forma y color resignificó el espacio público y le dio a la tradicional esquina nuevas connotaciones que debido al enfoque participativo del público, convirtió a los ciudadanos en parte de la obra, ya fuera en actividades programadas o simplemente al transitar por ella. Incluso, los colores de la creación se vieron reflejados en la vestimenta de quienes llegaron a mimetizarse con el espacio transformado.

Otro referente de interpretación de la ciudad desde el color es la propuesta de Simonetta Moro (2006), artista visual que fundamenta su obra en la creación de mapas y lugares a partir de diferentes tonalidades y relaciones cromáticas, para mezclar la realidad con la imaginación en un proceso de apropiación del espacio y expresión íntima de la ciudad.

Los mapas son el resultado de la superposición de distintas vistas aéreas, las cuales son mezcladas a partir del uso de diferentes materiales y texturas. La obra, gracias a la imaginación e interpretación personal de la artista, hace una abstracción de lugares reales y experiencias urbanas. 


\section{A MANERA DE SÍNTESIS}

El estudio del color urbano comprende variables que condicionan su análisis, como también contextos desde los que es posible la investigación. Las variables se remiten a la presencia de colores aleatorios, correspondientes a elementos cambiantes de la imagen urbana, entre ellos el clima y la hora del día. A su vez, los colores permanentes refieren componentes estables, tales como fachadas y calles.

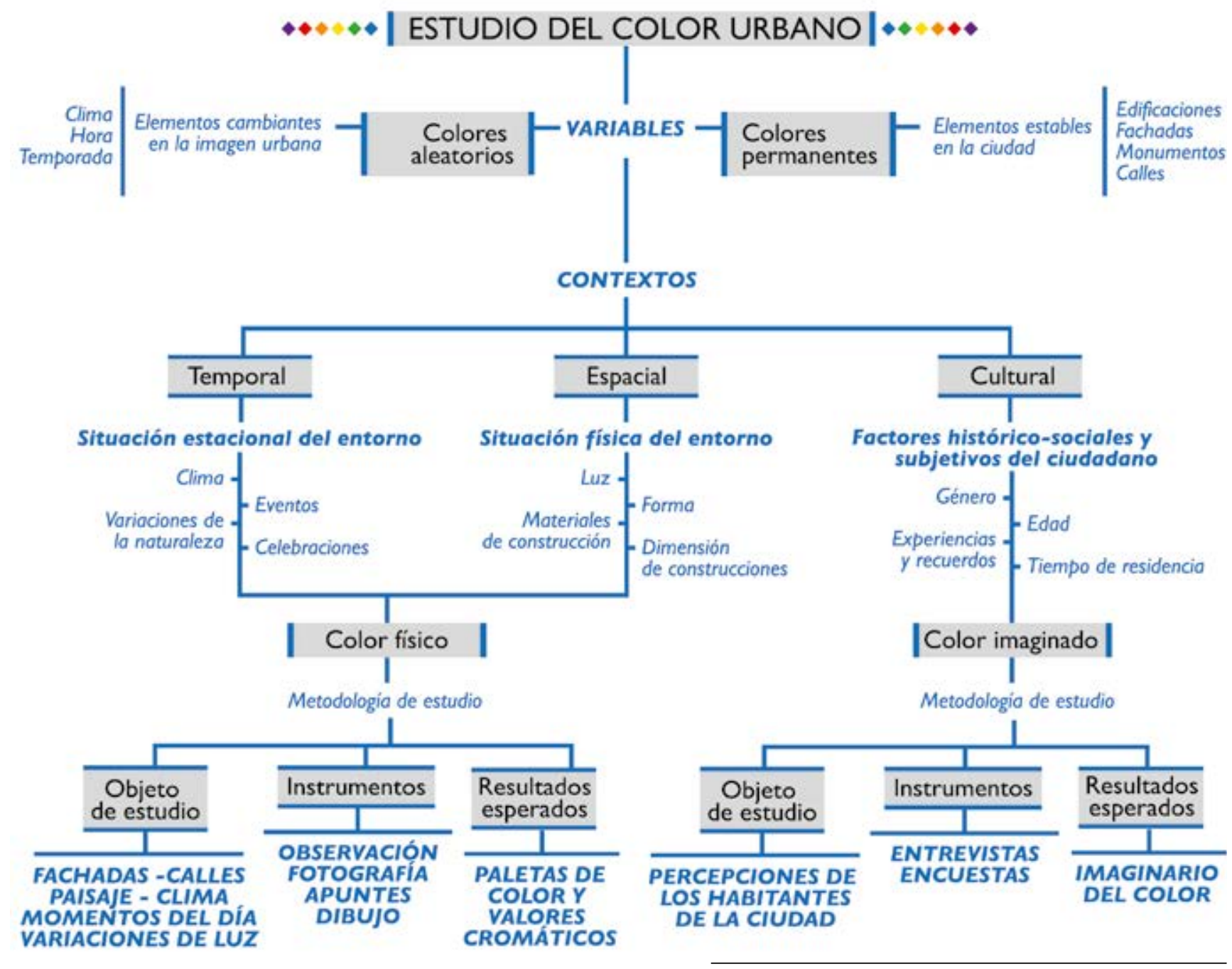

Figura 5. Mapa conceptual del proceso de estudio del color urbano Fuente: autor 
Como se ilustra en la figura 5 , en los contextos temporal, espacial y cultural se destacan diferentes procesos metodológicos de estudio del color urbano. El contexto temporal se relaciona con la situación estacional del entorno y es influido por elementos como el clima, los eventos y las coyunturas temporales de la ciudad. En el contexto espacial intervienen otros factores (la forma de los elementos urbanos, los materiales de construcción y la dimensión de las construcciones).

Estos dos contextos posibilitan la identificación del color físico; cabe indicar que a partir de instrumentos como observación, registros fotográficos y dibujos a color, se obtiene una síntesis del color urbano, expresado en paletas y valores cromáticos.

A diferencia de los contextos previos, el cultural está enfocado en el ciudadano y sus factores histórico-sociales y subjetivos. En este caso se toman en consideración el género, la edad, las percepciones y experiencias del habi- tante para identificar el color imaginado. Instrumentos como entrevistas y encuestas permiten un acercamiento al objeto de estudio, mientras que la sistematización y el análisis de la información obtenida en dichos sondeos conlleva al reconocimiento del imaginario del color.

\section{CONCLUSIONES}

El estudio del color urbano comprende al entorno como un emisor de información cromática, la cual posee diferentes connotaciones de acuerdo con el contexto en que se encuentre. En consecuencia, las investigaciones en este campo deben considerar las variables condicionantes del color de las ciudades, como son las tonalidades permanentes (referidas a los elementos estables) y aquellas aleatorias o efímeras, vinculadas a los factores cambiantes de la imagen urbana.

De la misma manera, la metodología de estudio debe contemplar la existencia de tres contextos: temporal (situación estacional del entorno), espacial (condición física) y cultural (factores histórico-sociales y subjetivos del ciudadano).

Existen dos enfoques metodológicos de apreciación cromática de la ciudad: el color físico, referido a las tonalidades existentes en la urbe, físicamente comprobables en calles, fachadas y paisaje; y el color imaginado o percibido por los habitantes, relacionado con sus percepciones cromáticas.

Para estudiar el color físico se han planteado metodologías basadas en instrumentos de recolección de información, tales como toma de muestras de materiales, dibujos a color, comparación con escalas de color, registro fotográfico y pixelación de la imagen. Todo ello se encamina a la obtención de paletas de color que resuman los valores cromáticos del lugar estudiado.

El análisis del color imaginado de las ciudades contempla la metodología de estudio del imaginario social, fundamentada en herramientas de investigación como el diario de campo, la observación, las entrevistas y la aplicación de encuestas a la ciudadanía. 
Así, se busca identificar las relaciones de los colores con los sentimientos y pensamientos en torno a la urbe, conjuntamente con las tonalidades que indican la relación entre esta y el ciudadano.
Ávila, M. M. (2010). Pocos entienden que el color es un material de construcción. Recuperado el 7 de junio de 2012, de http://www.lavoz.com.ar/ciudadanos/ pocos-entienden-que-el-color-es-un-material-de-construccion.

\section{REFERENCIAS} BIBLIOGRÁFICAS

Boeri, C. (2010). A perceptual approach to the urban color reading. En Zennaro P. Color and Light in Architecture (pp. 459-463). Verona: Knemesi.

Blair, G. (2012). At a Busy Intersection, Goins Beyond Red, Yellow and Green. Recuperado el 2 de agosto de 2012, de http://www.nytimes. com/2012/06/06/arts/design/color-jam-by-jessica-stockholder-opens-in-chicago.html?_r=0

Costa, J. (2003). Diseñar para los ojos. Barcelona, España: Design.

Eco, U. (1986). La estructura ausente. Barcelona, España: Lumen.

García, F. (2008). Fenómenos de ocupación del espacio público en Tunja. Tunja, Colombia: Universidad Santo Tomás de Tunja.

Gómez, A. (2006). Patrones de color: Interpretación visual de los valores cromáticos regionales en Caldas. Manizales, Colombia: Universidad de Caldas. 
Guerrero, Y. (2011). Expresiones físicas de los imaginarios en Tunja. Pretil, 24, pp. 19-36.

Iniciativa BMW para la innovación. (Productor). (2010a). Colores en serie, Plata: Reflex Multicolor [Documental]. Barcelona, España: TV3.

Iniciativa BMW para la innovación. (2010b). Pez de Plata: ciudad, creación y color. Barcelona, España: BMW Ibérica S.A.

Kadamani Abiyoma, S. (2010). Bogotá, la ciudad camaleónica. En U. d. Alicante (Ed.). IX Congreso Nacional del Color Alicante 2010 (pp. 141 - 144). Alicante, España: Publicaciones Universidad de Alicante.

Lenclos, J. (1999). Colors of the world. París, Francia: W.W. Norton \& Company Inc.

Moro, S. (2006). Simonetta Moro - Artist Statement. Recuperado el 6 de junio de 2010, de http://www.simonettamoro.com

Saldarriaga, A. (1984). Los colores de la calle. Bogotá, Colombia: Carlos Valencia Editores.

Sanz, J. (1993). El libro del color. Madrid, España: Alianza Editorial.

Silva, A. (2004). Bogotá Imaginada. Bogotá, Colombia: Taurus.

Silva, A. (2006). Los Imaginarios Urbanos (5 ed.). Bogotá, Colombia: Arango Editores.

Silva, A. \& Escoda, F. (2004). Barcelona Imaginada. Barcelona, España: Taurus.

Stockholder, J. (2012). Color Jam. Recuperado el 9 de agosto de 2012, de http:// artloop.chicagoloopalliance.com 